\title{
Parlons iaai. Ouvéa, Nouvelle-Calédonie de Daniel
} MIROUX

Isabelle Leblic

\section{(2) OpenEdition Journals}

\section{Édition électronique}

URL : http://journals.openedition.org/jso/6746

DOI : $10.4000 /$ jso. 6746

ISSN : $1760-7256$

Éditeur

Société des océanistes

Édition imprimée

Date de publication : 31 décembre 2012

Pagination : 279

ISBN : 978-2-85430-033-8

ISSN : 0300-953x

Référence électronique

Isabelle Leblic, "Parlons iaai. Ouvéa, Nouvelle-Calédonie de Daniel miroux », Journal de la Société des Océanistes [En ligne], 135 | 2012-2, mis en ligne le 26 janvier 2013, consulté le 24 septembre 2020 URL : http://journals.openedition.org/jso/6746 ; DOI : https://doi.org/10.4000/jso.6746 
Miroux Daniel, 2011. Parlons iaai. Ouvéa, NouvelleCalédonie, Paris, L'Harmattan, 326 p., bibliogr., 2 cartes, quelques dessins noir et blanc.

Cette collection « Parlons...», qui compte plus de 170 ouvrages, a été conçue pour répondre aux besoins des voyageurs qui souhaitent acquérir les connaissances de base sur un peuple, sa culture et sa langue, en faisant de chaque volume une méthode d'autoapprentissage linguistique avec des éléments de conversation courante et deux lexiques. C'est donc ici un ouvrage grand public qui, de plus, n'est pas le fait d'un linguiste ou d'un anthropologue. En 326 pages, son auteur, économiste de formation mais connaisseur d'Ouvéa, propose ici une découverte d'Ouvéa. Dans l'introduction, une présentation générale de l'île, de son peuplement et de son histoire permet de situer la langue iaai par rapport à celle fagauvea introduite par les migrations wallisiennes anciennes (pp. 7-14). Puis, la première partie propose une description très simplifiée de la langue (pp. 15-34). La deuxième partie se veut comme un guide de conversation courante (pp. 35-46). Enfin, la troisième partie revient sur la culture (pp. 4752) et sur l'arrivée des Européens (pp. 53-72). Enfin, l'ouvrage se termine par les deux lexiques, françaisiaai (pp. 73-190) puis iaai-français (pp. 191-320). Une courte bibliographie termine l'ensemble (pp. 321-323).

L'auteur n'en est pas à son premier ouvrage sur la question. Il avait déjà publié à Nouméa à l'Alliance Champlain dont il est le président plusieurs ouvrages sur la langue iaai : un dictionnaire français-iaai Tusi hwen iaai ae gaan (en 2007) et un manuel de conversation en langue iaai Tusi hwen iaai (en 2003). Malheureusement, ces deux premiers volumes n'ont pas eu une grande diffusion en dehors de la NouvelleCalédonie et furent vite épuisés ; ce dernier ouvrage reprend donc une synthèse de ceux-ci dans une édition mieux diffusée en métropole. On ne peut donc qu'en saluer la parution. Les puristes de la langue et/ou de la culture pourront trouver l'ensemble trop vulgarisateur et plein d'imprécisions. Mais sans doute le but de cet ouvrage qui n'est pas scientifique est-il ailleurs et son utilité pour les néophytes sera importante. On le lit facilement et c'est une première approche de l'île et de la langue iaai. Ceux qui voudront en savoir plus pourront compléter leur lecture par celle des écrits de Françoise Ozanne-Rivierre qui a longuement travaillé en tant que linguiste sur cette langue et qui fut l'auteur notamment d'un dictionnaire (1984) et d'une description linguistique de la langue (1976).

\section{RÉFÉRENCES CITÉES}

OZANNE-RIVIERre Fançoise, 1976. Le iaai, langue mélanésienne d'Ouvéa (Nouvelle-Calédonie). Phonologie, morphologie, esquisse syntaxique, Paris, SELAF, $245 \mathrm{p}$.

—, 1984. Dictionnaire iaai-français (Ouvéa, NouvelleCalédonie), suivi d'un lexique français-iaai, Paris, SELAF, coll. Langues et cultures du Pacifique 6, 179 p.

Isabelle LEBLIC, LACITO CNRS, Villejuif
NeICH Roger, 2008. Carved Histories. Rotorua Ngati Tarawhai Woodcarving, Auckland, Auckland University Press, XVI-424 p., appendices, bibliogr., index, 19 pl. couleur, très nombreuses ill. noir et blanc dans le texte.

Dans cette nouvelle présentation comme dans sa première édition (2001) qui faisait suite à un précédent volume (Painted Histories, 1993) explorant à la fois les données livrées par les colons et celles issues des Māori amenés à se servir du médium de la peinture importé par les Européens, le présent ouvrage, considéré par de nombreux spécialistes comme le meilleur livre de Roger Neich (1944-2010), n'avait jamais été décrit dans ces colonnes. Il convient aussi de l'évoquer pour commencer à honorer le souvenir de ce savant infatigable et généreux, brutalement arraché aux travaux multiples qu'il continuait à mener sur les arts du Pacifique après sa retraite de professeur et de conservateur, et qui allaient souvent bien au-delà de ceux de la Nouvelle-Zélande dont il était devenu le principal expert, et le plus sollicité. Ces dernières années, n'avait-il pas enquêté avec succès sur les sculptures (conventionnellement dénommées tino) de Nukuoro, d'abord à partir d'une figuration masculine en mains privées dont il défendit publiquement l'authenticité sourdement contestée dans les milieux marchands (Neich, 2008 - véritable leçon d'expertise), puis sur les circonstances de collecte de la grande figuration féminine du musée d'Auckland, authentifiant au passage son identification à Kawe, « la principale déesse des insulaires de Nukuoro » (Neich and Park, 2009) ? Tel était son souci d'approfondissement et d'élargissement permanents des connaissances, qui le conduisait encore, sans la moindre " confusion des genres », à autoriser de grandes maisons de ventes à reproduire dans leurs catalogues les avis qu'il formulait sur des pièces offertes aux enchères, du fait de leur intérêt esthétique ou historique.

Les « Ngati Tarawhai, a small Rotorua tribe famed for their wood-carving prowess » comme les avait définis R. Neich antérieurement (1996: 76), ne figurent pas sur la plupart des « cartes simplifiées des tribus māori » offertes par les ouvrages spécialisés, leur région de la Bay of Plenty étant généralement assignée aux seuls Te Arawa, ses principaux premiers occupants. Elle compte dix-sept lacs (capables d'accueillir un championnat du monde de ski nautique en 2007) et R. Neich, enquêtant auprès des Tarawhai dès 1971, a reconstitué leur histoire ponctuée de migrations de l'un à l'autre de ces lacs et d'épidémies qui les décimèrent, avant que les guerres du XIX ${ }^{\mathrm{e}}$ siècle et leurs suites ne modifient largement leur style de vie (chapitres 2, 3, 4, pp. 4-41). À ces remarquables pages d'ethnohistoire succèdent trois chapitres consacrés aux sculpteurs de la tribu, à leur statut et à leurs contacts avec les sculpteurs Ngati Pikiao (terme désignant divers sousgroupes Te Arawa), avec lesquels ils collaboraient fréquemment (pp. 42-85).

Les chapitres 8, 9 et 10 (pp. 101-145) s'attachent à préciser ce que recouvrent aujourd'hui les termes d' " art » et de « style », par rapport aux contenus qui leur étaient attribués au XIX ${ }^{\mathrm{e}}$ siècle tant du côté māori 